\title{
Hemophagocytic Lymphohistiocytosis Associated with Adult Vaccination: A Case of Cytokine Flurries
}

Zachary Liederman MD and Pearl Behl MD

\author{
About the Author \\ Zachary Liederman MD and Pearl Behl MD are Medical Residents at Queen's University. \\ Jill Dudebout MD is an Attending Hemotologist at Queen's University. Correspondence may be addressed to \\ Zachary.Liederman@queensu.ca.
}

\begin{abstract}
Hemophagocytic Lymphohistiocytosis (HLH) is an often-fatal condition characterized by an overactive but ineffective immune response. Secondary HLH in adults is often caused by infection, autoimmune disease, and malignancy. A 67-year-old woman presented to hospital with a five-day history of malaise beginning hours after receiving influenza and pneumococcal vaccinations. Her medical history was significant for rheumatoid arthritis, controlled with methotrexate and prednisone. In hospital, she was found to have a new febrile pancytopenia that persisted despite empiric antibiotics and discontinuation of methotrexate. The patient did not have any additional clinical or laboratory evidence of an infectious focus or rheumatoid arthritis flare. She had splenomegaly, but there was no definitive evidence of malignancy. Further testing revealed hepatitis, coagulopathy, and an elevated ferritin. Bone marrow biopsy demonstrated hemophagocytosis, and a diagnosis of HLH was made. She was successfully treated with a modified HLH 94 protocol, using dexamethasone and etoposide. Unfortunately, following hospital discharge after being well for 18 months with no HLH relapses, the patient was diagnosed with anaplastic T-cell lymphoma. HLH was likely secondary to a two-hit process with vaccinations in the context of immune dysregulation secondary to rheumatoid arthritis and subclinical lymphoma. To the best of our knowledge, vaccinations have not been linked to adult HLH; therefore, this case illustrates a potentially novel association in a susceptible patient. We propose that HLH should be considered in all patients with unexplained fever and cytopenias, and diagnosis should prompt evaluation for underlying causes, including vaccinations.
\end{abstract}

\section{Résumé}

La lymphohistiocytose hémophagocytaire est une affection souvent fatale, caractérisée par une réponse immunitaire exagérée, mais inefficace. La LH secondaire chez l'adulte est causée la plupart du temps par une infection, une maladie auto-immune ou une tumeur maligne. Voici le cas d'une femme de 67 ans qui se présente à l'hôpital après cinq jours de malaise à la suite de la vaccination antigrippale et antipneumococcique. L'anamnèse met en évidence une polyarthrite rhumatoïde stable grâce au méthotrexate et à la prednisone. À l'hôpital, elle connaît un épisode de pancytopénie fébrile qui persiste en dépit d'une antibiothérapie empirique et de l'arrêt du méthotrexate. L'investigation ne révèle aucun autre signe clinique ou biochimique d'un début d'infection ou d'une poussée de polyarthrite rhumatoïde. On note une splénomégalie, mais pas de signes concluants de tumeur maligne. Les analyses subséquentes révèlent une hépatite, une coagulopathie et une élévation de la ferritine. À la biopsie de la moelle osseuse, on observe une hémophagocytose, et le diagnostic de LH est posé. La patiente se rétablit grâce au traitement adoptant le protocole HLH 94 modifié faisant appel à la dexaméthasone et à l'étoposide. Elle sort de l'hôpital, mais, malheureusement, après 18 mois de stabilité sans rechute de la LH, 
on lui diagnostique un lymphome anaplasique à grandes cellules. La LH découlait probablement d'un processus à deux facettes, soit la vaccination dans un terreau de dérèglement immunitaire en raison de la polyarthrite rhumatoïde et d'un lymphome subclinique. Pour autant que nous sachions, rien ne liait jusqu'à maintenant la vaccination à l'apparition de la LH chez l'adulte; le présent cas serait le premier à révéler un tel lien chez une personne sensible. Nous proposons d'envisager la possibilité d'une LH dans tous les cas de fièvre et de cytopénie inexpliquées, et le diagnostic devrait s'accompagner de l'évaluation de la cause sous-jacente qui pourrait être la vaccination.

\section{Case}

A 67-year-old woman with long-standing rheumatoid arthritis presented to hospital with a five-day history of malaise. Her symptoms began within hours following influenza (Vaxigrip - 2012 inactivated influenza vaccine trivalent types A and B) and pneumococcal (Pneumovax 23 -23-valent polysaccharide) vaccinations. She had received influenza vaccinations without incident in the past; however, this was her first pneumococcal vaccination exposure. She was febrile (maximum oral temperature $38.9^{\circ} \mathrm{C}$ ) but otherwise hemodynamically stable with no apparent infectious focus or rheumatoid flare. Physical examination suggested chronic rheumatoid arthritis in her hands and feet. In addition to rheumatoid arthritis, her medical history was significant for hypertension, osteoporosis, and bilateral hip replacements. Home medications included methotrexate, prednisone, folic acid, alendronate, trandolopril, oxycodone, and amitryptyline. She had been taken off subcutaneous methotrexate one year earlier because of leukopenia. She was restarted after a rheumatoid flare and had since been stable with no further cytopenias on methotrexate $25 \mathrm{mg}$ injected weekly.

Laboratory investigations in hospital revealed a mild chemical hepatitis (AST $270 \mathrm{U} / \mathrm{L}$, ALT $201 \mathrm{U} / \mathrm{L}$, ALP $224 \mathrm{U} / \mathrm{L}$ ) and pancytopenia (hemoglobin $88 \mathrm{~g} / \mathrm{L}$, leukocyte count $0.810^{9} / \mathrm{L}$, platelets $4410^{9} / \mathrm{L}$, neutrophils $0.3210^{9} / \mathrm{L}$, lymphocytes 0.35 109/L, monocytes $0.12109 / \mathrm{L})$. Ferritin was $35856 \mu \mathrm{g} / \mathrm{L}$ with a $\mathrm{CRP}$ and ESR of $54.3 \mathrm{mg} / \mathrm{L}$ and $8 \mathrm{~mm} / \mathrm{hr}$, respectively. Creatinine peaked at $186 \mu \mathrm{mol} / \mathrm{L}$. Septic workup and extensive laboratory testing for viral infection (EBV, HIV, CMV, parvovirus, HAV, $\mathrm{HBV}, \mathrm{HCV}, \mathrm{HSV}$, varicella, measles), was negative, with the exception of a positive hepatitis B core antibody. Follow-up hepatitis B " $\mathrm{e}$ " antigen, hepatitis B " $\mathrm{e}$ " antibody, and hepatitis B DNA viral load were not detected. Subsequently, the core antibody result was determined to be a false positive. Imaging including computed tomography (CT) scan of the thorax, abdomen, and pelvis showed splenomegaly. Previous abdominal ultrasound described a spleen within normal limits. Blood work from one month earlier showed a chronically elevated CRP but was otherwise unremarkable.

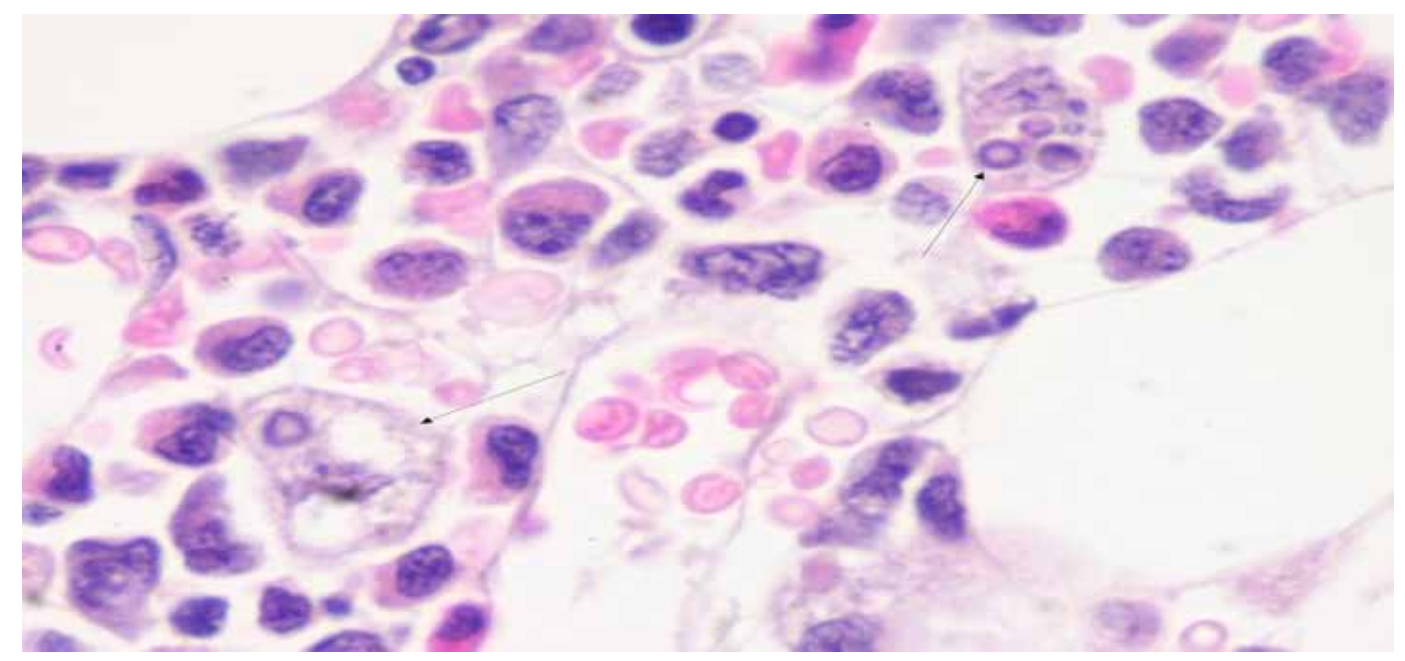

Figure 1. Bone marrow biopsy demonstrating hemophagocytosis. Black arrows show reactive histiocytes with phagocytosis of red blood cells and platelets. 
Broad-spectrum antibiotics were initiated and methotrexate was stopped. However, the patient continued to be febrile, without improvement in her blood counts. This was accompanied by a significant decrease in fibrinogen and an elevated INR. Despite this, two and a half weeks after the onset of her symptoms, she remained clinically well with only minimal fatigue and no major complications. Hematology was consulted and a bone marrow biopsy showed hemophagocytosis. Bone marrow was very weakly positive for T-cell clonality by PCR; however, CT imaging and physical exam did not reveal any clear evidence of malignancy. Her clinical presentation of fever, splenomegaly, hypofibrinogenemia, pancytopenia, hepatitis, elevated ferritin, and hemophagocytosis met criteria for the diagnosis of hemophagocytic lymphohistiocytosis (HLH).

She was initially managed supportively and then started on a modified HLH 2004 protocol with dexamethasone and etoposide for eight weeks. Rapid clinical and biochemical improvement was observed, accentuated by a ferritin decrease of over $50 \%$ within two days. Her blood counts steadily improved and reached baseline levels over three months.

The patient had regular hematology follow-up, and despite no relapses of HLH, 18 months after initial presentation was diagnosed with anaplastic T-cell lymphoma (ALK-). This was discovered incidentally on ultrasound evaluation for leg swelling. It is suspected that she had clonal lymphoid hematopoesis at the time of HLH; however, investigations as described above did not reveal clear evidence of lymphoma at that time.

Overall, HLH was likely secondary to a two-hit process, with vaccinations triggering HLH in the presence of immune dysregulation secondary to rheumatoid arthritis and subclinical T-cell lymphoma.

\section{Discussion}

HLH, also known as hemophagocytic syndrome, is an inflammatory disorder characterized by an overactive but ineffective immune response. Impaired $\mathrm{T}$ and natural killer cell cytotoxicity prevents down-regulation of the immune response, leading to sustained histiocytosis and cytokine elevation. Defects in the immune cascade may be genetic (primary) or acquired (secondary), with primary HLH almost exclusive to young children. ${ }^{1}$ HLH in adults has been associated with various triggers, including infection, autoimmune disease, malignancy, and medications. ${ }^{2}$

The clinical picture of HLH is typically non-specific. Common findings include fever, fatigue, hepatosplenomegaly, rash, and neurological symptoms ranging from headache to menigismus. ${ }^{1}$ Hemophagocytosis is not pathognomic for HLH and might also be found in other conditions, including blood transfusions and infections. ${ }^{1,3}$ A retrospective pediatric study showed high ferritin levels (greater than 10, $000 \mu \mathrm{g} / \mathrm{L}$ ) to be highly specific for HLH. The 2004 HLH diagnostic criteria include eight common clinical and laboratory findings (Table 1), but have never been tested in an adult population. The criteria also incorporate laboratory tests not commonly available. ${ }^{2}$ Lack of definitive diagnostic criteria and the nonspecific clinical picture make the diagnosis of HLH challenging in adults.

Once diagnosed, identifying the trigger can have implications for both treatment and prognosis. Infection- associated HLH may have a milder course, in particular compared to patients with underlying malignancy. ${ }^{4,5}$ Overall, $\mathrm{HLH}$ is very aggressive, with a mortality rate as high as $72 \%$ in an adult case series. ${ }^{6}$ Early treatment should be directed against both the underlying cause and the immune response. The HLH 2004 protocol for primary HLH uses an eight-week course of dexamethasone, etoposide, cyclosporine, and methotrexate plus stem cell transplant and continuation therapy for refractory patients. ${ }^{7}$ Combinations of glucocorticoids, IVIG, biologics, and etoposide have been used with success in adults with secondary HLH. ${ }^{2}$

A wide range of microorganisms, including influenza viruses, have been linked to HLH, with EBV being the most common implicated virus. ${ }^{1,8}$ Autoimmune $\mathrm{HLH}$, a similar disease to macrophage activation syndrome, predominately occurs with systemic lupus erythematosus (SLE) and adult Still's disease but has also been documented in rheumatoid arthritis. In the setting of autoimmune disease, HLH primarily occurs at diagnosis or with concomitant infection. ${ }^{9}$ Medications including biologics, antibiotics, anticonvulsants, and methotrexate have also been implicated as triggers.

Table 1. Adapted HLH 2004 Diagnostic Criteria. Molecular evidence of HLH or the presence of five of eight criteria establishes a diagnosis of $\mathrm{HLH}^{7}$

\section{HLH Diagnostic Criteria}

Fever $\geq 38.5^{\circ} \mathrm{C}$ for 5 days

Splenomegaly

Cytopenias (affecting at least 2 lineages)

Hemoglobin $<90 \mathrm{~g} / \mathrm{L}$

Platelets $<100 \times 103 / \mathrm{mL}$

Neutrophils $<1$ x103/mL

Hypofibrinogenemia $(<1.5 \mathrm{~g} / \mathrm{L})$ or Hypertriglyceridemia

(fasting levels $\geq 2 \mathrm{mmol} / \mathrm{L}$ )

Hemophagocytosis in bone marrow, spleen, lymph nodes, or liver

Low or absent natural killer cell activity

Serum Ferritin $\geq 500 \mu \mathrm{g} / \mathrm{L}$

Soluble CD25 $\geq 2400 \mathrm{U} / \mathrm{ml}$ 
Lymphoma is the most frequent malignant etiology, and ALCL is commonly linked to HLH. ${ }^{2}$ In this setting, the diagnosis of ALCL is predominately made concurrently with that of HLH and associated with malignant bone marrow invasion. ${ }^{10} \mathrm{In}$ our case, the presence of T-cell clonality on bone marrow PCR suggests occult ALCL at the time of presentation. While the long delay between HLH and the development of overt lymphoma is unusual, treatment with etoposide might have obscured the diagnosis. Etoposide can also lead to secondary malignancies, but the risk is low at cumulative doses under $1200 \mathrm{mg} / \mathrm{m} 2$, and secondary T-cell lymphoma following etoposide is rare. ${ }^{11}$ Little is known about the occurrence of HLH following immunizations, but in children, cases have been observed. ${ }^{12,13}$ Furthermore, a cutaneous histiocytic reaction with a similar pathophysiology to HLH was observed in a woman after having pneumococcal vaccination..$^{14}$

To the best of our knowledge, there are no documented cases of HLH associated with vaccination in adults. Although immune dysregulation secondary to rheumatoid arthritis and subclinical ALCL likely contributed to her presentation, both lymphoma and autoimmune associated HLH almost always occur in the presence of overt disease exacerbations. The development of our patient's symptoms immediately following vaccination, and the absence of HLH relapse despite persistent lymphoma and rheumatoid arthritis, suggests immunizations as a triggering factor. This unique case of HLH identifies a potential association with immunizations in a susceptible patient.

In summary, HLH should be considered in all adults with unexplained febrile cytopenias. Diagnosis prompts aggressive therapy and a thorough evaluation for underlying causes, including recent vaccinations. Lastly, our case highlights the importance for extended follow-up and malignancy monitoring in HLH patients.

\section{Conflict of interest: none declared.}

\section{References}

1. Jordan MB, Allen CE, Weitzman S, et al. How I treat hemophagocytic lymphohistiocytosis. Blood 2011;118:4041-52.

2. Larroche C. Hemophagocytic lymphohistiocytosis in adults: diagnosis and treatment. Joint Bone Spine 2012;79:356-61.

3. Gupta A, Weitzman S, Abdelhaleem M. The role of hemophagocytosis in bone marrow aspirates in the diagnosis of hemophagocytic lymphohistiocytosis. Pediatr Blood Cancer 2008;50:192-4.

4. Takahashi N, Chubachi A, Kume M, et al. A clinical analysis of 52 adult patients with hemophagocytic syndrome: the prognostic significance of the underlying diseases. Int J Hematol 2001;74:209-13.

5. Tseng YT, Sheng WH, Lin BH, et al. Causes, clinical symptoms, and outcomes of infectious diseases associated with hemophagocytic lymphohistiocytosis in Taiwanese adults. J Microbiol Immunol Infect 2011;44:191-7.

6. Shabbir M, Lucas J, Lazarchick J, et al. Secondary hemophagocytic syndrome in adults: a case series of 18 patients in a single institution and a review of literature. Hematol Oncol 2011;29:100-6.

7. Henter JI, Horne A, Arico M, et al. HLH-2004: Diagnostic and therapeutic guidelines for hemophagocytic lymphohistiocytosis. Pediatr Blood Cancer 2007;48:124-31.

8. Rouphael NG, Talati NJ, Vaughan C, et al. Infections associated with haemophagocytic syndrome. Lancet Infect Dis 2007;7:814-22.

9. Dhote R, Simon J, Papo T, et al. Reactive hemophagocytic syndrome in adult systemic disease: report of twenty-six cases and literature review. Arthritis Rheum 2003;49:633-9.

10. Tong H, Ren Y, Liu H, et al. Clinical characteristics of T-cell lymphoma associated with hemophagocytic syndrome: comparison of T-cell lymphoma with and without hemophagocytic syndrome. Leuk Lymphoma 2008;49:81-7.

11. Smith MA, Rubinstein L, Anderson JR, et al. Secondary leukemia or myelodysplastic syndrome after treatment with epipodophyllotoxins. J Clin Oncol 1999;17:569-77.

12. Otagiri T, Mitsui T, Kawakami T, et al. Haemophagocytic lymphohistiocytosis following measles vaccination. Eur J Pediatr 2002;161:494-6.

13. Ghanaiee RM, Shiari R, Karimi A, et al. A case series report of Iranian children; Hemophagocytic Lymphohistiocytosis syndrome. Arch Pediatr Infect Dis 2012;1:31.

14. Bassis AV, Fairley JA, Ameln RT, Swick BL. Cutaneous Rosai-Dorfman disease following pneumococcal vaccination. J Am Acad Dermatol 2011;65:890-2. 